\title{
Monitoring uterine contractility in mice using a transcervical intrauterine pressure catheter
}

\author{
Michael F Robuck ${ }^{1}$, Christine M O’Brien², Kelsi M Knapp ${ }^{1}$, Sheila D Shay ${ }^{3}$, James D West ${ }^{3}$, \\ J M Newton ${ }^{4}$, James C Slaughter ${ }^{5}$, Bibhash C Paria ${ }^{1}$, Jeff Reese ${ }^{1,2}$ and Jennifer L Herington ${ }^{1,6}$ \\ ${ }^{1}$ Division of Neonatology, Department of Pediatrics, Vanderbilt University Medical Center, Nashville, Tennessee, \\ USA, ${ }^{2}$ Department of Biomedical Engineering, Vanderbilt University, Nashville, Tennessee, USA, ${ }^{3}$ Division of Allergy, \\ Pulmonary, and Critical Care Medicine, Department of Medicine, Vanderbilt University Medical Center, Nashville, \\ Tennessee, USA, ${ }^{4}$ Division of Maternal Fetal Medicine, Department of Obstetrics and Gynecology, Vanderbilt \\ University Medical Center, Nashville, Tennessee, USA, ${ }^{5}$ Department of Biostatistics, Vanderbilt University Medical \\ Center, Nashville, Tennessee, USA and ${ }^{6}$ Department of Pharmacology, Vanderbilt University, Nashville, \\ Tennessee, USA
}

Correspondence should be addressed to J L Herington; Email: Jennifer.I.herington@vanderbilt.edu

\begin{abstract}
In mouse models used to study parturition or pre-clinical therapeutic testing, measurement of uterine contractions is limited to either ex vivo isometric tension or operative intrauterine pressure (IUP). The goal of this study was to: (1) develop a method for transcervical insertion of a pressure catheter to measure in vivo intrauterine contractile pressure during mouse pregnancy, (2) determine whether this method can be utilized numerous times in a single mouse pregnancy without affecting the timing of delivery or fetal outcome and (3) compare the in vivo contractile activity between mouse models of term and preterm labor (PTL). Visualization of the cervix allowed intrauterine pressure catheter (IUPC) placement into anesthetized pregnant mice (plug=day 1 , delivery = day 19.5$)$. The amplitude, frequency, duration and area under the curve (AUC) of IUP was lowest on days 16-18, increased significantly $(P<0.05)$ on the morning of day 19 and reached maximal levels during by the afternoon of day 19 and into the intrapartum period. An AUC threshold of $2.77 \mathrm{mmHg}$ discriminated between inactive labor (day $19 \mathrm{am}$ ) and active labor (day 19 pm and intrapartum period). Mice examined on a single vs every experimental timepoint did not have significantly different IUP, timing of delivery, offspring number or fetal/neonatal weight. The IUP was significantly greater in LPS-treated and RU486-treated mouse models of PTL compared to time-matched vehicle control mice. Intrapartum IUP was not significantly different between term and preterm mice. We conclude that utilization of a transcervical IUPC allows sensitive assessment of in vivo uterine contractile activity and labor progression in mouse models without the need for operative approaches.

Reproduction (2018) 155 447-456
\end{abstract}

\section{Introduction}

Proper uterine contractility is not only required for labor progression and the control of postpartum hemorrhage, but also for the transport of semen and gametes, as well as embryo implantation. Inadequate uterine contractility contributes to retrograde menstruation, endometriosis, infertility, ectopic pregnancies and miscarriages (Lesny et al. 1999, Bulletti et al. 2002, Kissler et al. 2004, Leyendecker et al. 2004, Bulletti \& de Ziegler 2005, Aguilar \& Mitchell 2010). Conversely, uterine hypercontractility is a main cause for primary dysmenorrhea (Aguilar \& Mitchell 2010).

In women, uterine activity (frequency, strength and duration of contractions) during labor is monitored clinically by either: external palpation, electrohysterography (EHG; also known as uterine electromyography), magnetomyography (Eswaran et al.
2002), external tocodynamometry or internal tocodynamometry utilizing a transcervical intrauterine pressure catheter (IUPC) (Pauli \& Repke 2016). External tocodynamometry is useful for long-term, non-invasive monitoring of contraction frequency and duration; however, IUPC accurately monitors these contractile parameters as well as amplitude with minimal artifact. While IUPC is the gold standard for quantitatively measuring IUP and activity (Hadar et al. 2015) in the United States, its use is typically restricted to high-risk pregnancies to monitor labor progress (Pauli \& Repke 2016). The rationale behind the limited use of IUPC is risk of infection, due to its insertion into the amniotic space following rupture of the fetal membranes. It is estimated that approximately $20 \%$ of the deliveries in the United States are monitored using an IUPC (Choby 2011). 
Rodent models are instrumental research tools to study pregnancy, preterm labor (PTL) and term labor, including, but not limited to: (1) transgenic and knockout mice used to decipher the role of a specific gene in mediating the timing of labor or mechanisms underlying uterine contractility, (2) determining the existence and location of a uterine pacemaker (Fuchs \& Poblete 1970, Miller et al. 1989, Lammers et al. 1994, 2015) and (3) pre-clinical testing of novel therapeutics to regulate uterine contractility for the prevention of PTL, labor induction or control of postpartum hemorrhage. In rodent models utilized for pregnancy-related studies, uterine contractions or pressure have been measured by either ex vivo isometric tension, abdominal and uterine surface electromyography (Buhimschi \& Garfield 1996, Buhimschi et al. 1998) or in vivo pressure recordings using either surgical placement of an IUPC (Vickery 1979, Buhimschi \& Garfield 1996, Buhimschi et al. 1998, Mahendroo et al. 1999, Word et al. 2005) or IUPC-radiotelemeter directly into the uterus (Pierce et al. 2010, Rada et al. 2015). Isometric tension recording is an excellent ex vivo functional assay to measure uterine myometrial contractility (Pak et al. 1994, Norman et al. 1997, Baumbach et al. 2012, Robinson \& Wray 2012). Similarly, IUPCradiotelemetry is a valuable in vivo method to study uterine contractile pressure throughout pregnancy and labor in non-anesthetized mice (Pierce et al. 2010, Rada et al. 2015).

Transcervical IUPC placement in mice would provide a rapid, reliable and quantifiable measure of contraction frequency, duration, strength and resting uterine tone, using similar clinical methods as in humans (Serr 1974). Here, we present a description for the placement of an IUPC through the cervical os of anesthetized pregnant mice for intermittent measurement of intrauterine contractile pressure. Our objectives were to: (1) optimize the experimental parameters including catheter size and anesthetic agent, (2) examine whether a transcervically placed pressure catheter is sensitive enough to detect changes in IUP between different late-stage pregnancy days and intrapartum, (3) determine whether this method can be utilized numerous times in a single mouse pregnancy without affecting the timing of delivery and fetal outcome and (4) compare the in vivo contractile activity between mouse models of term and PTL.

\section{Materials and methods}

\section{Mice}

All experiments involving the use of mice had prior approval from the Institutional Animal Care and Use Committee at the Vanderbilt University Medical Center. Adult CD-1 wild-type (Charles River Laboratories) mice were housed with free access to food and water in 12-h light: 12-h darkness cycles. Virgin
CD-1 (8-12 weeks, 25-30g) female mice were bred overnight with fertile males, and the presence of a copulatory vaginal plug was considered day 1 of pregnancy. Maternal weight was recorded on antepartum days 16, 18 and 19 and postpartum day 1 . Timing of delivery was monitored using infrared video surveillance. The number of offspring, as well as their weights, was recorded on the morning of postnatal day 1 . At necropsy, uteri were examined for signs of injury or fetal loss caused by placement of the pressure catheter, and the intact uterine weight was recorded as well as the uterine diameter by use of a caliper. For each of the experiments described below, timepoint data were obtained from a minimum of 5 different animals.

\section{Mouse models of preterm birth}

A progesterone receptor antagonist, mifepristone (also known as RU486; Sigma) was dissolved in $30 \mu \mathrm{L} 100 \% \mathrm{ETOH}$ and then added to $200 \mu \mathrm{L}$ sesame oil (Sigma) prior to subcutaneous injection $(0.3 \mathrm{mg} / 230 \mu \mathrm{L}$ per mouse) into the nape of the neck at 7:00 h on day 15 of pregnancy. Similarly, control animals received vehicle $(30 \mu \mathrm{L} 100 \%$ ETOH diluted $200 \mu \mathrm{L}$ in sesame oil). Lipopolysaccharide (LPS; $100 \mu$; serotype O55:B5, Sigma) dissolved in $100 \mu \mathrm{L}$ sterile normal saline or vehicle control saline $(100 \mu \mathrm{L})$ was injected (i.p.) at 7:00 h on day 15 of pregnancy.

\section{Intrauterine pressure: catheter placement and recording}

On antepartum days 16, 18 and 19, as well as intrapartum, defined as the delivery of at least one pup, mice were anesthetized with either: $1 \%$ or $2 \%$ isoflurane (inhaled using a precision vaporizer and either $100 \%$ oxygen or room air), tribromoethanol (125-250 mg/kg, i.p.) or urethane (1-1.2 g/ $\mathrm{kg}$, i.p.; Sigma). Anesthetized mice were placed on a heating pad and then a speculum tube $(0.5 \mathrm{~cm}$ width, $1.5 \mathrm{~cm}$ length) was inserted into the vaginal canal to visualize the cervix. A pressure catheter (Millar 1.4F and 3.5F, SPR-671 and SPR524, respectively; ADInstruments, Colorado Springs, USA) was inserted transcervically to $3-6 \mathrm{~cm}$ depth, which was a predetermined length to pass the pressure sensing IUPC tip beyond the uterocervical junction. Mice were anesthetized and catheterized for each of the IUP recordings. After intrauterine contractions became rhythmic with consistent amplitude and frequency, baseline intrauterine contractile pressure was recorded (measured in $\mathrm{mmHg}$ ) using PowerLab 8/35SP and PCU-2000 (ADInstruments) hardware. The IUPC was calibrated at baseline $(0 \mathrm{mmHg})$ and $25 \mathrm{mmHg}$ on each experimental day using the PCU-2000. The pressure catheter was cleaned with $1 \%$ tergazyme and then disinfected in CIDEX OPA per manufacturer's instructions for $30 \mathrm{~min}$ before each use in mice, as well as between mice.

Intrauterine contractile pressure recordings were analyzed using LabChart 7 Pro software (ADInstruments). The contractile activity was assessed for a 10-min period of time by: mean amplitude and frequency, AUC relative to baseline (normalized by dividing it by the exact number of seconds during the period), as well as Montevideo units (the sum of amplitudes during the 10-min period of time). 


\section{Respiratory rate, heart rate and oxygen saturation measurement}

Respiratory rate (breaths per minute), heart rate (beats per minute) and oxygen saturation (\%) were measured using a MouseOX Plus Pulse oximeter and physiological monitor (STARR Life Sciences, Oakmont, USA). Six measurements were recorded per mouse at each experimental timepoint.

\section{Statistical analysis}

For clarity, results are shown as mean \pm S.E.M. Statistical analysis was performed using GraphPad Prism, version 6.0e software (GraphPad Software), and $P<0.05$ was considered significant. A two-way ANOVA was used for statistical comparison between gestational days 16, 18, 19 and intrapartum of mice used to measure IUP on a single timepoint vs every experimental timepoint. In mice measured over multiple days, we calculated all pairwise Pearson correlation coefficients and found the correlations were small $(0.03<r<0.13)$. Conditional probability was calculated as the proportion of IUP above/below a threshold per gestational day or intrapartum period. The timing of delivery, offspring number and weight were analyzed using a one-way ANOVA to compare mice used to measure IUP on a single timepoint vs every experimental timepoint. Maternal weight was analyzed using a two-way ANOVA for statistical comparison between mice used for a single timepoint vs every experimental timepoint for IUP studies on gestational days 16, 18, 19 and postpartum day 1 . To compare mouse models of PTL vs saline-treated control mice at multiple hours after treatment, a two-way ANOVA was performed. When ANOVA results were significant, pairwise tests were conducted using a Bonferroni adjustment for multiple comparisons. A Pearson correlation analysis was performed to compute the coefficient of determination $\left(R^{2}\right)$.

\section{Results}

The laboratory setup used to monitor IUP changes during mouse pregnancy is shown in Fig. 1. A pressure control unit (PCU-2000) served as a two-channel amplifier and interface between the pressure catheter and PowerLab data acquisition system (Fig. 1A). A speculum tube (Fig. 1B) was used to visualize the mouse cervix for IUPC placement. Figure 1C shows a close up image of the pressure-sensitive transducer located at the tip of the catheter. In an initial subset of mice, postmortem visualization of the IUPC (Fig. 1D) allowed the determination of the length needed to surpass the uterocervical junction for each gestational day examined.

Optimal recordings of IUP were achieved by adjusting the position of the catheter. Two sizes (1.4F and 3.5 F) of pressure catheter were tested in order to determine which produced uterine contractile recordings that were similar to those previously reported using a surgically placed IUPC in mice. While there was no statistical difference in IUP measurements (Fig. 2A) obtained

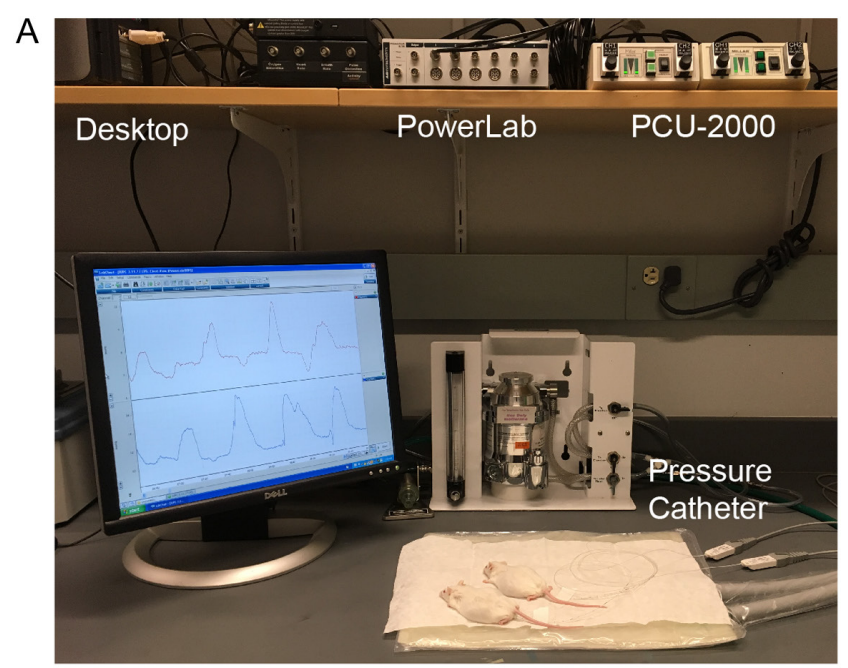

B
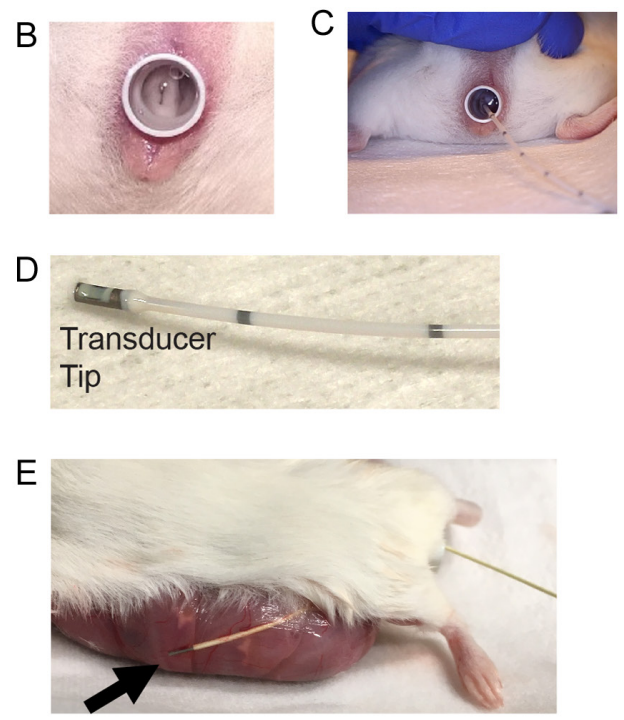

Figure 1 Laboratory system for IUP recording and pressure catheter insertion. (A) Equipment used to monitor and measure IUP. (B and C) A speculum tube used to visualize the mouse cervix for pressure catheter placement. (D) Close up picture of a 3.5 F MikroTip Catheter. (E) Photomicrograph taken postmortem on day 19 of pregnancy to show intrauterine placement of the catheter (indicated by arrow).

from the two different sized pressure catheters, the 1.4 F catheter was more difficult to guide through the visible cervix, unlike that of the $3.5 \mathrm{~F}$ catheter. Therefore, subsequent studies utilized only the $3.5 \mathrm{~F}$ catheter.

In order to minimize the effect of anesthetic agents on uterine tone, three different anesthetic agents were tested based on reports of smaller hemodynamic effects or prior use in IUP studies: isoflurane, tribromoethanol (also known as avertin) and urethane (Mahendroo et al. 1999, Roth et al. 2002, Janssen et al. 2004, Word et al. 2005). There was no statistically significant difference between IUP measurements obtained by using avertin, $1 \%$ isoflurane or urethane as the anesthetic agent. In 


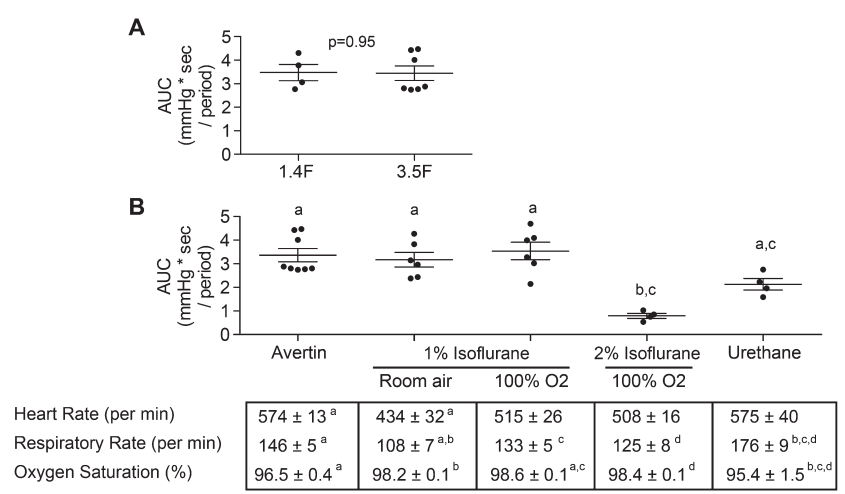

Figure 2 Optimization of catheter size and anesthetic agent used for IUPC. (A) Term (day 19) pregnant mice were used to determine which size of pressure catheter ( $1.4 \mathrm{~F}$ vs $3.5 \mathrm{~F}$ ) provided the most reproducible measurement of IUP, which was recorded and then analyzed for AUC relative to baseline. (B) Anesthetic agents were tested to establish, which had the least impact on IUP, as well as maternal heart rate, respiratory rate and oxygen saturation from term mice. Paired superscripts (a, b, c and d) indicate significantly $(P<0.05)$ different means within a row.

contrast, $2 \%$ isoflurane significantly $(P<0.05)$ inhibited IUP. While isoflurane is most commonly mixed with $100 \% \mathrm{O}_{2}$ for use as an anesthetic agent, the effect of hyperoxia on in vivo IUP or contractility is unknown. Therefore, the anesthetic effect of $1 \%$ isoflurane mixed with $100 \% \mathrm{O}_{2}$ or normal air $\left(21 \% \mathrm{O}_{2}, 78 \% \mathrm{~N}_{2}\right.$ and $0.4 \% \mathrm{CO}_{2}$ ) on IUP was compared. After 30 - to 40 -min exposure to $1 \%$ isoflurane mixed with room air, a decrease was observed in the respiratory rate and IUP, but not for mice anesthetized with $1 \%$ isoflurane mixed with $100 \% \mathrm{O}_{2}$. By using a pulse oximeter, significant $(P<0.05)$ differences were quantitatively detected in the heart rate, respiratory rate and oxygen saturation between the anesthetic agents (Fig. 2B). Based on the above results, avertin or $1 \%$ isoflurane mixed with $100 \% \mathrm{O}_{2}$ were found to be optimal anesthetics for IUPC measurements.

Next, we examined whether a transcervicallyplaced pressure catheter could detect differences in IUP between gestational day 16, 18, 19 and intrapartum, and whether mice could be utilized at multiple gestational time points to measure IUP, without negatively impacting IUP, timing of delivery, litter size or fetal outcome. Optimal intrauterine contractile pressure curves were rhythmic with an average contractile integral (AUC), amplitude, frequency, duration and Montevideo units per gestational day, as reported in Table 1. The IUP recorded on days 16 and 18 of mouse pregnancy was low in amplitude, infrequent and were not significantly different from one another (Fig. 3). However, IUP significantly increased on the morning (8:00-11:00h) of day 19 and further increased during the afternoon (noon-16:00h) of day 19 of pregnancy, where it remained elevated until the intrapartum period (occurring between 19:00 h on day 19 to 3:00 h on day 20). In post hoc analysis, we identified an AUC threshold of $1.4 \mathrm{mmHg} / \mathrm{s}$ where $88 \%$ of the measurements on the morning of day 19 were above the threshold (sensitivity) and $100 \%$ of the measurements on day 18 were below the threshold (specificity). Moreover, an AUC threshold of $2.77 \mathrm{mmHg} / \mathrm{s}$ discriminates between inactive labor (the morning of day 19) and active labor (the afternoon of day 19 and intrapartum period) with $100 \%$ sensitivity and $94 \%$ specificity. The IUP was not significantly different between mice examined on a single experimental day compared to animals with measurements taken at all experimental time points (gestational days 16, 18 and 19). Moreover, measuring IUP at a single or multiple gestational time points did not negatively impact the increasing maternal weight $(P>0.05)$ with advancing gestation, timing of delivery $(P=0.91)$, offspring number $(P=0.31)$ or fetal weight $(P=0.44)$ (Fig. 4). Following delivery of pups, there were no physical signs of uterine trauma due to insertion of the IUPC at multiple timepoints during pregnancy and active labor (data not shown). No dams were lost due to poor catheter placement, and no stillborn or resorbed fetuses were observed at the site of IUPC placement.

Key differences between mouse and human pregnancy, which could impact uterine contractions during labor, include the number of offspring and uterine structure. Therefore, we examined the relationship between IUP and the number of offspring, intact uterine weight, uterine diameter and pup weight, as it changed during pregnancy (Table 2). On average, the greatest coefficients of determination were between IUP (AUC,

Table 1 Average IUP recorded at different CD-1 mouse pregnancy timepoints.

\begin{tabular}{|c|c|c|c|c|}
\hline \multirow[b]{2}{*}{ IUP } & \multicolumn{4}{|c|}{ Day of pregnancy } \\
\hline & $16(n=7)$ & $18(n=5)$ & 19 a.m. $(n=11)$ & 19 p.m. $(n=7)$ \\
\hline $\mathrm{AUC}\left(\mathrm{mmHg}{ }^{*} \mathrm{~s}\right) /$ period & $0.50 \pm 0.04^{\mathrm{a}}$ & $1.07 \pm 0.17^{\mathrm{a}}$ & $2.06 \pm 0.18^{b}$ & $3.80 \pm 0.45^{c}$ \\
\hline Amplitude (mmHg) & $3.15 \pm 0.40^{\mathrm{a}}$ & $5.29 \pm 0.71^{\mathrm{a}}$ & $13.86 \pm 2.16^{b}$ & $19.68 \pm 3.74^{c}$ \\
\hline Frequency (\#/10 min) & $6 \pm 1^{\mathrm{a}}$ & $7 \pm 1^{\mathrm{a}}$ & $12 \pm 1^{\mathrm{b}}$ & $11 \pm 1^{\mathrm{b}}$ \\
\hline Duration (s) & $13.33 \pm 1.11^{\mathrm{a}}$ & $14.54 \pm 0.99^{a}$ & $20.98 \pm 1.18^{\mathrm{b}}$ & $22.88 \pm 2.92^{\mathrm{b}}$ \\
\hline Montevideo units & $24.90 \pm 4.24^{\mathrm{a}}$ & $58.97 \pm 21.34^{\mathrm{a}}$ & $109.41 \pm 6.30^{b}$ & $237.20 \pm 28.71^{c}$ \\
\hline
\end{tabular}

IUP obtained at a single experimental timepoint. Listed are mean \pm S.E.M. and those with different superscripts $(\mathrm{a}, \mathrm{b}$ and $\mathrm{c})$ indicate significantly $(P<0.05)$ different means within a row.

$\mathrm{A} \cup \mathrm{C}$, area under the curve; IUP, intrauterine pressure; $\mathrm{mmHg}$, millimeters of mercury. 
A day 16

气

day 18

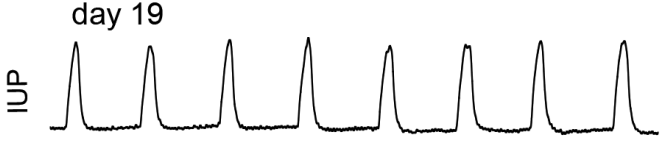

Intrapartum

B

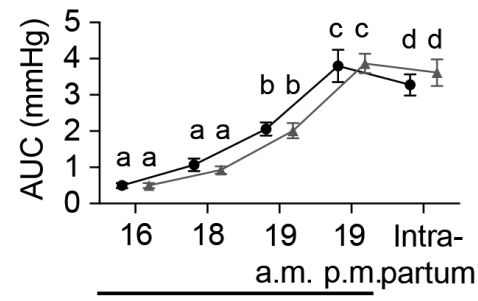

Day of Pregnancy

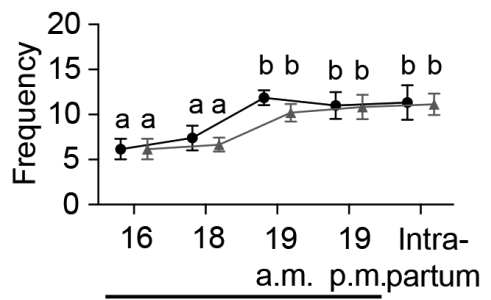

Day of Pregnancy

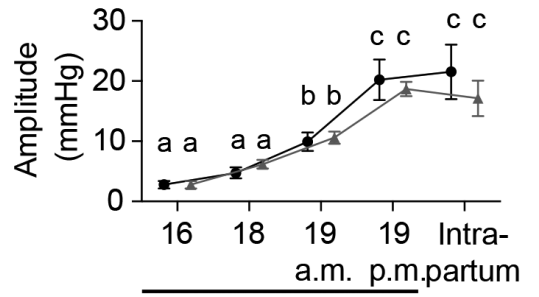

Day of Pregnancy

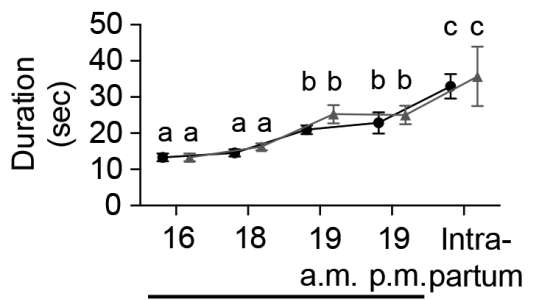

Day of Pregnancy
- Single day

$₫$ Multiple Days

Figure 3 IUP changes during normal pregnancy and active labor. (A) Representative IUP recordings obtained from CD-1 mice during antepartum days 16, 18 and 19 and intrapartum. IUP measurements were compared between mice used for a single gestational day (blue circles) compared to mice used for all gestational days examined (red circles). (B) Recordings were analyzed for AUC relative to baseline, amplitude, frequency, duration and Montevideo units. $P<0.05$ between all timepoints examined, except day 16 vs day 18 , and day 19:00 h vs intrapartum. $P>0.05$ for single vs multiple timepoints.

amplitude and Montevideo units) and uterine diameter $\left(R^{2}: 0.66-0.70\right)$ as well as between IUP and fetal weight $\left(R^{2}: 0.67-0.70\right)$. Conversely, offspring number and maternal weight were observed to correlate the least $\left(R^{2}\right.$ : 0.07-0.14 and $R^{2}: 0.11-0.15$, respectively) with IUP during pregnancy. In other words, at least $66 \%$ of the variation in IUP during pregnancy can be explained by the relationship to uterine diameter and fetal weight.

Finally, IUP changes in two mouse models of PTL were monitored and compared to IUP changes observed during term pregnancy and labor. Given that measuring IUP at multiple gestational time points did not negatively affect IUP recordings (Fig. 3) or pregnancy outcomes (Fig. 4), intrauterine contractile pressure was measured at two time points prior to delivery, as well as intrapartum. Since LPS-treated mice are reported to deliver earlier than RU486-treated mice (Migale et al. 2016), IUP was measured at different experimental time points for the two mouse models of PTL (Fig. 5). By $4 \mathrm{~h}$ post injection, IUP was already significantly $(P<0.05)$ greater in LPS-treated mice compared to saline-treated control mice. At $8 \mathrm{~h}$ post injection, IUP was significantly $(P<0.05)$ greater than that at $4 \mathrm{~h}$ post injection and remained elevated into the intrapartum period of LPStreated mice. At $8 \mathrm{~h}$ post injection, RU486-treated mice had significantly $(P<0.05)$ greater IUP compared to control mice. By $16 \mathrm{~h}$ post injection, the IUP of RU486treated mice had doubled and remained elevated into the intrapartum period. LPS-treated and RU486-treated mice were monitored for their timing of delivery, which occurred at significantly $(P<0.05)$ different time points $(13.7 \mathrm{~h}$ vs $23.6 \mathrm{~h}$ post-injection, respectively), as well as significantly earlier than control-treated mice. The intrapartum IUP was compared between both mouse models of PTL (LPS- and RU486-induced) and normal term labor (gestation day 19.5), but no significant differences were observed in the AUC, amplitude, frequency or duration of contractions (Table 3). 
- Control

- Single day IUPC

$\triangle$ Multiple days IUPC
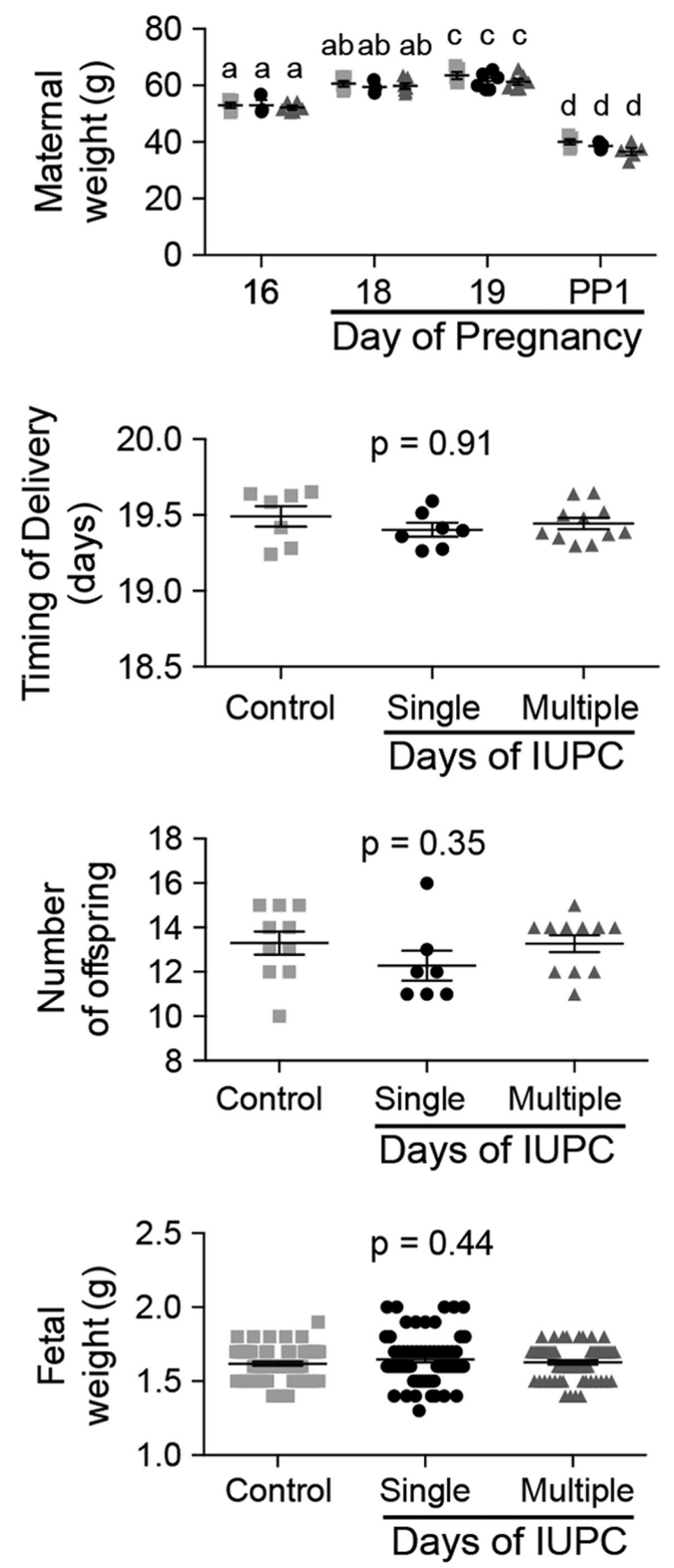

Figure 4 Effect of repeated IUP monitoring on timing of delivery and fetal outcome. Mice were anesthetized with $1 \%$ isoflurane mixed with $100 \% \mathrm{O}_{2}$ on gestation days 16,18 and 19 (morning and afternoon), to record IUP from either a single timepoint (b/ue circles) or multiple gestational timepoints (red circles). Impact on pregnancy outcome was monitored by differences in maternal weight, timing of delivery, the number of offspring, and fetal weight compared to control mice that were not used for IUPC studies. The timing of delivery was monitored using infrared video surveillance.
Moreover, the Montevideo units calculated from the intrapartum period of mice undergoing term and PTL were similar.

\section{Discussion}

Currently, an ex vivo isometric contractility assay using uterine tissue strips is the most widely utilized method to evaluate uterine function in mouse models used to study parturition. However, there is a lack of noninvasive or minimally invasive tools to rapidly assess in vivo uterine contractile activity. In the present study, we established a transcervical IUPC method that can successfully distinguish pre-labor (morning of day 19) and labor (afternoon of day 19 and intrapartum period) associated contractile changes in pregnant mice. Moreover, we found that this transcervical IUPC method can effectively monitor intrauterine contractile pressure at multiple gestational time points in a single mouse without compromising the timing of delivery or fetal outcomes. We established that at least $66 \%$ of the variation in IUP during mouse pregnancy can be explained by the relationship to uterine diameter and fetal weight. Additionally, we confirmed that IUP of experimentally induced PTL was similar to that of normal, term labor of pregnant mice. Thus, transcervical IUPC approaches appear to be practical and very useful for monitoring IUP changes during the progression of labor in mice.

The intrauterine contractile activities measured and reported in this study are in agreement to those from prior studies utilizing surgically implanted IUPCs in rats and mice. IUP was low amplitude $(3-5 \mathrm{mmHg})$ and irregular on day 16-18 of pregnancy (Fuchs \& Poblete 1970, Buhimschi \& Garfield 1996), but developed into regular contractions with increased intensity and duration on the day of parturition (Deis \& Pickford 1964). During the intrapartum period, the contraction duration and AUC reached maximal levels (Shi et al. 2008, Mackay et al. 2009). Similar to studies utilizing surgically implanted IUP-radiotelemeters in mice (Pierce et al. 2010, Rada et al. 2015), the non-surgical, transcervical IUPC approach described here was able to distinguish between pre-labor (day 19 morning) and labor (day 19 afternoon and intrapartum) contraction patterns in mice. The amplitude, and therefore AUC, of IUP changes recorded in the current study was greater than values previously reported from surgical IUPC studies, but lower than surgically implanted IUPCtelemetry studies. One potential explanation includes the level of anesthesia required for surgical placement of the catheter and subsequent IUP recordings.

Although Buhimschi and Garfield reported uterine activity that was similar between anesthetized and nonanesthetized rats, they noted large fluctuations (artifact signals) in their recording using non-anesthetized animals due to movement of rats (Buhimschi \& Garfield 1996). 
Table 2 Relationship between IUP and maternal, fetal biometric changes during CD-1 mouse pregnancy.

\begin{tabular}{|c|c|c|c|c|c|c|c|c|}
\hline & \multicolumn{3}{|c|}{ Day of pregnancy } & \multirow[b]{2}{*}{ AUC } & \multicolumn{4}{|c|}{ IUP coefficients of determination $\left(R^{2}\right)$} \\
\hline & $16(n=7)$ & $18(n=6)$ & $19(n=5)$ & & Amplitude & Frequency & Duration & MVU \\
\hline Maternal weight (g) & $53.62 \pm 1.35$ & $55.73 \pm 1.28$ & $58.3 \pm 4.46$ & 0.13 & 0.11 & 0.05 & 0.06 & 0.15 \\
\hline Intact uterine weight (g) & $14.73 \pm 0.91$ & $21.43 \pm 0.81$ & $24.37 \pm 2.47$ & 0.52 & 0.54 & 0.43 & 0.49 & 0.60 \\
\hline Uterine diameter (mm) & $11.33 \pm 0.21$ & $12.60 \pm 0.06$ & $13.95 \pm 0.34$ & 0.68 & 0.70 & 0.52 & 0.50 & 0.66 \\
\hline Number of offspring & $15 \pm 1$ & $12 \pm 1$ & $14 \pm 1$ & 0.14 & 0.14 & 0.26 & 0.20 & 0.07 \\
\hline Fetal weight (g) & $0.50 \pm 0.02$ & $1.23 \pm 0.06$ & $1.48 \pm 0.07$ & 0.68 & 0.70 & 0.71 & 0.56 & 0.67 \\
\hline
\end{tabular}

Listed are mean \pm S.E.M. and Pearson coefficient of determination $R^{2}$.

$\mathrm{AUC}$, area under the curve; $\mathrm{g}$, grams; IUP, intrauterine pressure; $\mathrm{mmHg}$, millimeters of mercury.

Thus, we decided to use short-term general anesthesia in our study. It is well established that injectable as well as inhaled anesthetics cause depressed cardiovascular and respiratory function. Specifically, pentobarbitol and a xylazine-ketamin mixture are reported to have the greatest hemodynamic effects, yet, serve as the most commonly utilized anesthetic agents in animal studies (Furukawa et al. 1998). In our initial study, we chose to limit the anesthetics investigated to those with either a prior use in surgical IUPC studies (avertin and urethane) or demonstrated to cause the least hemodynamic effects (inhaled isoflurane). We found that $2 \%$ inhaled isoflurane was the only anesthetic agent to significantly inhibit IUP. However, urethane as well as $1 \%$ isoflurane mixed with room air had a significant dampening effect on the respiratory rate, while avertin use in room air had significantly diminished oxygen saturation. It appears that $1 \%$ isoflurane mixed with $100 \%$ oxygen is best suited for our repetitive IUP studies. Moreover, given the lack of pharmacological grade avertin and urethane, their use is becoming more restricted in research involving animals.

There are advantages and disadvantages to utilizing a transcervical IUPC compared to other methods used to monitor in vivo uterine contractile activity of animal models for studying pregnancy and labor. The
A

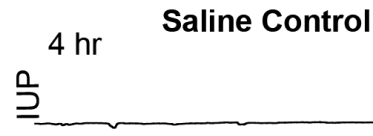

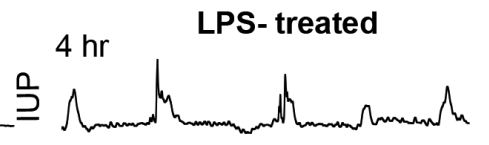

$8 \mathrm{hr}$

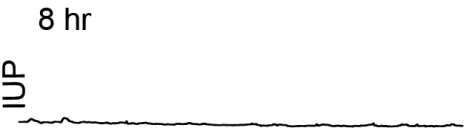

$16 \mathrm{hr}$
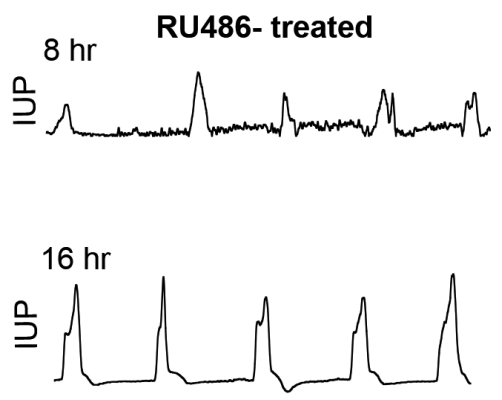

Intrapartum

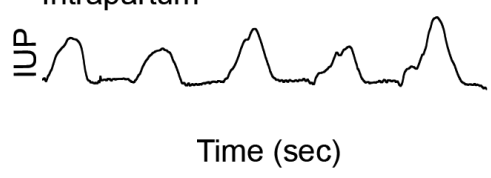

B
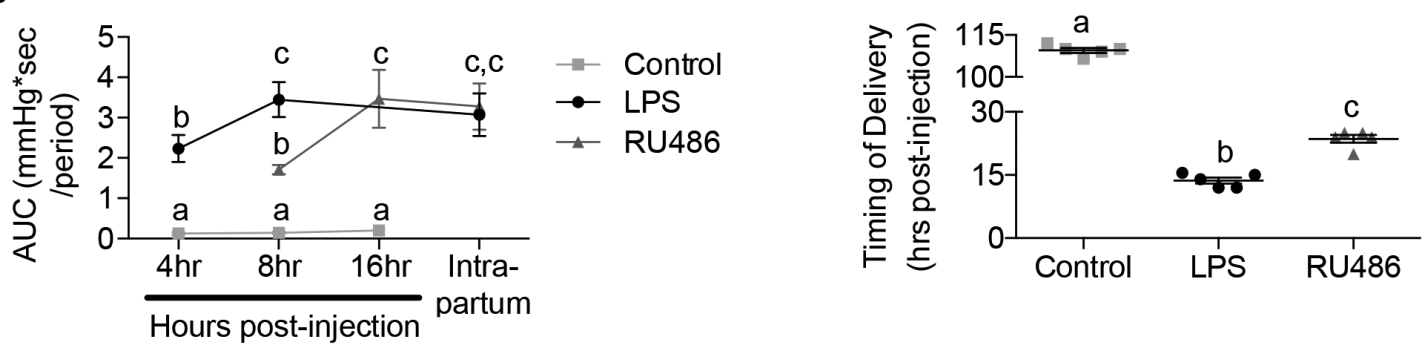

Figure 5 IUP changes in experimentally induced mouse models of preterm labor. (A) Representative IUP recordings at indicated hours posttreatment with saline, lipopolysaccharide (LPS) or mifepristone (RU486) on day 15 of pregnancy. (B) IUP recordings were analyzed for AUC relative to baseline. Mice were placed on infrared video surveillance to monitor timing of delivery (hours post treatment). 
Table 3 Comparison of intrapartum IUP between term and preterm labor mouse models.

\begin{tabular}{|c|c|c|c|c|}
\hline & \multirow[b]{2}{*}{ Term $(n=12)$} & \multicolumn{2}{|c|}{ Preterm } & \multirow[b]{2}{*}{$P$ value } \\
\hline & & $\operatorname{LPS}(n=7)$ & RU486 $(n=8)$ & \\
\hline AUC $\left(\mathrm{mmHg}^{*} \mathrm{~s}\right) /$ period & $3.62 \pm 0.27$ & $3.69 \pm 0.49$ & $3.19 \pm 0.47$ & 0.67 \\
\hline Amplitude (mmHg) & $18.88 \pm 3.03$ & $17.87 \pm 1.92$ & $24.96 \pm 5.29$ & 0.39 \\
\hline Frequency (\#, $10 \mathrm{~min})$ & $12 \pm 1$ & $12 \pm 2$ & $8 \pm 1$ & 0.07 \\
\hline Duration (s) & $33.40 \pm 4.00$ & $23.64 \pm 0.72$ & $27.60 \pm 1.52$ & 0.12 \\
\hline Montevideo units & $206.94 \pm 28.71$ & $242.18 \pm 24.00$ & $203.80 \pm 33.32$ & 0.46 \\
\hline
\end{tabular}

Listed are mean \pm S.E.M. and $P$ values from a one-way ANOVA.

$\mathrm{AUC}$, area under the curve; $\mathrm{mmHg}$, millimeters of mercury.

advantages include non-surgical IUPC placement, ability to use at multiple experimental timepoints without negatively impacting pregnancy outcome or timing of delivery, precise as well as quantifiable recording of intrauterine contractile pressure activity and the relatively inexpensive equipment costs. The disadvantages of using a non-surgical IUPC are the intermittent, non-continuous recording of in vivo uterine contractile activity throughout pregnancy and the need to anesthetize mice. A primary weakness of our study is the inability to observe the exact intrauterine location of the pressure catheter during the recordings, which can be overcome in the future by utilizing ultrasound-guided catheter placement.

The benefit of using a surgically placed IUPC through the uterine wall is the ability to view the precise location where contractile recordings are being obtained. Furthermore, a specific benefit of utilizing a surgically implanted IUPC-radiotelemeter is that it allows continuous recording throughput pregnancy in non-anesthetized mice. Another optimal non-surgical method to monitor IUP activity involves recording uterine electromyographic activity from the abdominal surface. This approach was developed by Garfield and colleagues using pregnant animals (Buhimschi \& Garfield 1996, Buhimschi et al. 1998) and has been shown equally effective in women (Freundlich \& Wingate 1973, Wolfs \& van Leeuwen 1979, Buhimschi et al. 1997, Hadar et al. 2015). Unfortunately, this method is yet to be adapted for utilization in experimental mouse models to study pregnancy and parturition.

In women, the amplitude of IUP increases from $25-30 \mathrm{mmHg}$ to $60-65 \mathrm{mmHg}$ during labor progression (Buhimschi et al. 2003). In the current study, we found that the amplitude of IUP also increases from an average of $14 \mathrm{mmHg}$ on the morning of the expected day of delivery to $20 \mathrm{mmHg}$ during the pre-partum period. While the contractile amplitude of the pregnant mouse is slightly lower than women, the Montevideo units appear to be similar to women, at least $200 \mathrm{MVUs}$, as a result of greater contractile frequency observed in mice. Although mice are a polytocous species, the number of offspring was not found to be correlative with IUP during pregnancy. However, we found that at least $66 \%$ of the variation in IUP during mouse pregnancy can be explained by the relationship to uterine diameter and fetal weight, likely the result of 'uterine stretch' as the stimulus for contractile activity.

Gradual increase in IUP leading to parturition in humans is well established. Moreover, several transgenic mouse models of altered parturition due to insufficient uterine activity substantiate the importance of uterine contractions required for successful parturition (Ratajczak \& Muglia 2008). However, little attention has been given to development of non-surgical methods for repeated and accurate measurement of IUP to assess labor onset in mice. The findings of this study established that non-surgical placement of an IUPC through the cervix could serve as an effective method to measure and monitor IUP changes during the progression of labor in anesthetized pregnant mice, while avoiding adverse pregnancy outcomes. The ability to repeatedly monitor IUP in mice prevents the need for tissue harvest at multiple gestational timepoints and promotes the principles of reduction and refinement in animal research. Future studies utilizing transcervical IUPC would also benefit pre-clinical mouse studies to determine the in vivo efficacy of novel tocolytic and uterotonic compounds on uterine contractile pressure (Herington et al. 2015).

\section{Declaration of interest}

The authors declare that there is no conflict of interest that could be perceived as prejudicing the impartiality of the research reported.

\section{Funding}

This project was supported by research funds $(J \mathrm{~L} \mathrm{H})$ from: Vanderbilt CTSA award number KL2TR000446 from the National Center for Advancing Translational Sciences; Vanderbilt CTSA grant UL1 TR000445 from NCATS/NIH; the Vanderbilt Preventing adverse Pregnancy outcomes and Prematurity (Pre3) Initiative, a Trans-Institutional Program, award. This work was also supported by the Eunice Kennedy Shriver National Institute of Child Health and Human Development (Grants HD088830 (J L H), HD080148 (B C P), HD081121 to (J R)). 


\section{References}

Aguilar HN \& Mitchell BF 2010 Physiological pathways and molecular mechanisms regulating uterine contractility. Human Reproduction Update 16 725-744. (https://doi.org/10.1093/humupd/dmq016)

Baumbach J, Shi SQ, Shi L, Balducci J, Coonrod DV \& Garfield RE 2012 Inhibition of uterine contractility with various tocolytics with and without progesterone: in vitro studies. American Journal of Obstetrics and Gynecology 206 254.e251-255.e251. (https://doi.org/10.1016/j. ajog.2011.12.011)

Buhimschi C \& Garfield RE 1996 Uterine contractility as assessed by abdominal surface recording of electromyographic activity in rats during pregnancy. American Journal of Obstetrics and Gynecology 174 744-753. (https://doi.org/10.1016/S0002-9378(96)70459-3)

Buhimschi C, Boyle MB \& Garfield RE 1997 Electrical activity of the human uterus during pregnancy as recorded from the abdominal surface. Obstetrics and Gynecology 90 102-111. (https://doi.org/10.1016/ S0029-7844(97)83837-9)

Buhimschi C, Boyle MB, Saade GR \& Garfield RE 1998 Uterine activity during pregnancy and labor assessed by simultaneous recordings from the myometrium and abdominal surface in the rat. American Journal of Obstetrics and Gynecology 178 811-822. (https://doi.org/10.1016/ S0002-9378(98)70498-3)

Buhimschi CS, Buhimschi IA, Malinow AM, Saade GR, Garfield RE \& Weiner CP 2003 The forces of labour. Fetal and Maternal Medicine Review 14 273-307. (https://doi.org/10.1017/S0965539503001128)

Bulletti C \& de Ziegler D 2005 Uterine contractility and embryo implantation. Current Opinion in Obstetrics and Gynecology 17 265-276. (https://doi.org/10.1097/01.gco.0000169104.85128.0e)

Bulletti C, De Ziegler D, Polli V, Del Ferro E, Palini S \& Flamigni C 2002 Characteristics of uterine contractility during menses in women with mild to moderate endometriosis. Fertility and Sterility 77 1156-1161. (https://doi.org/10.1016/S0015-0282(02)03087-X)

Choby BA 2011. Intrauterine pressure catheter insertion. In Pfenninger and Fowler's Procedures for Primary Care, pp 1155-1157.Editors: John L. Pfenninger and Grant C. Fowler; Elsevier Mosby; Philadelphia, PA

Deis RP \& Pickford M 1964 The effect of autonomic blocking agents on uterine contractions of the rat and the guinea-pig. Journal of Physiology 173 215-225. (https://doi.org/10.1113/jphysiol.1964.sp007453)

Eswaran H, Preissl H, Wilson JD, Murphy P, Robinson SE \& Lowery CL 2002 First magnetomyographic recordings of uterine activity with spatialtemporal information with a 151-channel sensor array. American Journal of Obstetrics and Gynecology 187 145-151. (https://doi.org/10.1067/ mob.2002.123031)

Freundlich JJ \& Wingate MB 1973 An evaluation of an external electromyographic system for recording uterine contractions during labor. American Journal of Obstetrics and Gynecology 116 822-826. (https://doi.org/10.1016/0002-9378(73)91015-6)

Fuchs AR \& Poblete VF Jr 1970 Oxytocin and uterine function in pregnant and parturient rats. Biology of Reproduction 2 387-400. (https://doi. org/10.1095/biolreprod2.3.387)

Furukawa S, MacLennan MJ \& Keller BB 1998 Hemodynamic response to anesthesia in pregnant and nonpregnant ICR mice. Laboratory Animal Science 48 357-363.

Hadar E, Biron-Shental T, Gavish O, Raban O \& Yogev Y 2015 A comparison between electrical uterine monitor, tocodynamometer and intra uterine pressure catheter for uterine activity in labor. Journal of Maternal-Fetal and Neonatal Medicine 28 1367-1374. (https://doi.org/10.3109/14767 058.2014.954539)

Herington JL, Swale DR, Brown N, Shelton EL, Choi H, Williams $\mathrm{CH}$, Hong CC, Paria BC, Denton JS \& Reese J 2015 High-throughput screening of myometrial calcium-mobilization to identify modulators of uterine contractility. PLOS ONE 10 e0143243. (https://doi.org/10.1371/ journal.pone.0143243)

Janssen BJ, De Celle T, Debets JJ, Brouns AE, Callahan MF \& Smith TL 2004 Effects of anesthetics on systemic hemodynamics in mice. American Journal of Physiology: Heart and Circulatory Physiology 287 H1618-H1624. (https://doi.org/10.1152/ajpheart.01192.2003)

Kissler S, Siebzehnruebl E, Kohl J, Mueller A, Hamscho N, Gaetje R, Ahr A, Rody A \& Kaufmann M 2004 Uterine contractility and directed sperm transport assessed by hysterosalpingoscintigraphy (HSSG) and intrauterine pressure (IUP) measurement. Acta Obstetricia et
Gynecologica Scandinavica $83 \quad 369-374 . \quad$ (https://doi.org/10.1111/ j.0001-6349.2004.00412.x)

Lammers WJ, Arafat K, el-Kays A \& el-Sharkawy TY 1994 Spatial and temporal variations in local spike propagation in the myometrium of the 17-day pregnant rat. American Journal of Physiology 267 C1210-C1223. (https://doi.org/10.1152/ajpcell.1994.267.5.C1210)

Lammers WJ, Stephen B, Al-Sultan MA, Subramanya SB \& Blanks AM 2015 The location of pacemakers in the uteri of pregnant guinea pigs and rats. American Journal of Physiology Regulatory, Integrative and Comparative Physiology 309 R1439-R1446. (https://doi.org/10.1152/ ajpregu.00187.2015)

Lesny P, Killick SR, Robinson J, Raven G \& Maguiness SD 1999 Junctional zone contractions and embryo transfer: is it safe to use a tenaculum? Human Reproduction 14 2367-2370. (https://doi.org/10.1093/ humrep/14.9.2367)

Leyendecker G, Kunz G, Herbertz M, Beil D, Huppert P, Mall G, Kissler S, Noe M \& Wildt L 2004 Uterine peristaltic activity and the development of endometriosis. Annals of the New York Academy of Sciences $\mathbf{1 0 3 4}$ 338-355. (https://doi.org/10.1196/annals.1335.036)

Mackay LB, Shi SQ, Garfield RE \& Maner WL 2009 The effect of bilateral pelvic neurectomy on uterine and abdominal electrical and pressure activity, as measured by telemetry in conscious, unrestrained pregnant rats. Journal of Perinatal Medicine 37 313-319. (https://doi.org/10.1515/ JPM.2009.075)

Mahendroo MS, Porter A, Russell DW \& Word RA 1999 The parturition defect in steroid 5alpha-reductase type 1 knockout mice is due to impaired cervical ripening. Molecular Endocrinology 13 981-992. (https://doi.org/10.1210/mend.13.6.0307)

Migale R, MacIntyre DA, Cacciatore S, Lee YS, Hagberg H, Herbert BR, Johnson MR, Peebles D, Waddington SN \& Bennett PR 2016 Modeling hormonal and inflammatory contributions to preterm and term labor using uterine temporal transcriptomics. BMC Medicine 14 86. (https:// doi.org/10.1186/s12916-016-0632-4)

Miller SM, Garfield RE \& Daniel EE 1989 Improved propagation in myometrium associated with gap junctions during parturition. American Journal of Physiology 256 C130-C141. (https://doi.org/10.1152/ ajpcell.1989.256.1.C130)

Norman JE, Ward LM, Martin W, Cameron AD, McGrath JC, Greer IA \& Cameron IT 1997 Effects of CGMP and the nitric oxide donors glyceryl trinitrate and sodium nitroprusside on contractions in vitro of isolated myometrial tissue from pregnant women. Journal of Reproduction and Fertility 110 249-254. (https://doi.org/10.1530/jrf.0.1100249)

Pak SC, Bertoncini D, Meyer W, Scaunas D, Flouret G \& Wilson L Jr 1994 Comparison of binding affinity of oxytocin antagonists to human and rat uterine oxytocin receptors and their correlation to the rat uterine oxytocic bioassay. Biology of Reproduction 51 1140-1144. (https://doi. org/10.1095/biolreprod51.6.1140)

Pauli JM \& Repke JT. 2016. Insertion of intrauterine pressure catheters. In UpToDate. (available at: http://www.uptodate.com)

Pierce SL, Kutschke W, Cabeza R \& England SK 2010 In vivo measurement of intrauterine pressure by telemetry: a new approach for studying parturition in mouse models. Physiological Genomics 42 310-316. (https://doi.org/10.1152/physiolgenomics.00058.2010)

Rada CC, Pierce SL, Grotegut CA \& England SK 2015 Intrauterine telemetry to measure mouse contractile pressure in vivo. Journal of Visualized Experiments 98 e52541. (https://doi.org/10.3791/52541)

Ratajczak CK \& Muglia LJ 2008 Insights into parturition biology from genetically altered mice. Pediatric Research 64 581-589. (https://doi. org/10.1203/PDR.0b013e31818718d2)

Robinson H \& Wray S 2012 A new slow releasing, H(2)S generating compound, GYY4137 relaxes spontaneous and oxytocin-stimulated contractions of human and rat pregnant myometrium. PLOS ONE 7 e46278. (https://doi.org/10.1371/journal.pone.0046278)

Roth DM, Swaney JS, Dalton ND, Gilpin EA \& Ross J Jr 2002 Impact of anesthesia on cardiac function during echocardiography in mice. American Journal of Physiology: Heart and Circulatory Physiology 282 H2134-H2140. (https://doi.org/10.1152/ajpheart.00845.2001)

Serr DM 1974 Methods for recording the continuous fetal heart rate and uterine contractions. Clinical Obstetrics and Gynecology 1 169-190.

Shi SQ, Maner WL, Mackay LB \& Garfield RE 2008 Identification of term and preterm labor in rats using artificial neural networks on uterine electromyography signals. American Journal of Obstetrics 
and Gynecology 198 235.e231-234.e231. (https://doi.org/10.1016/j. ajog.2007.08.039)

Vickery BH 1979 Effects of naproxen on uterine contractility in vivo. Prostaglandins and Medicine 2 299-315. (https://doi.org/10.1016/01614630(79)90064-8)

Wolfs GM \& van Leeuwen M 1979 Electromyographic observations on the human uterus during labour. Acta Obstetricia et Gynecologica Scandinavica Supplement 90 1-61. (https://doi. org/10.3109/00016347909156375)

Word RA, Landrum CP, Timmons BC, Young SG \& Mahendroo MS 2005 Transgene insertion on mouse chromosome 6 impairs function of the uterine cervix and causes failure of parturition. Biology of Reproduction 73 1046-1056. (https://doi.org/10.1095/biolreprod.105.042663)

Received 20 October 2017

First decision 8 January 2018

Revised manuscript received 5 February 2018

Accepted 2 March 2018 